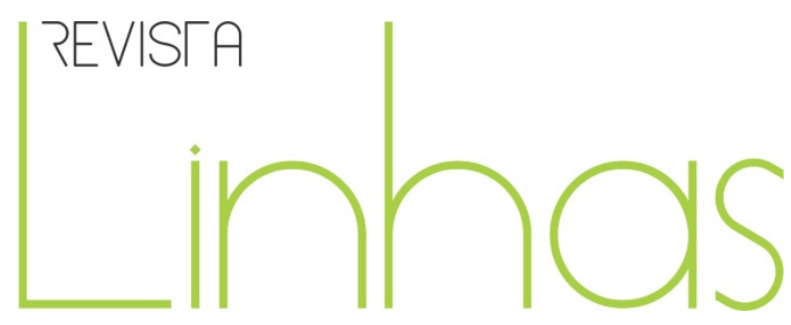

\title{
O currículo cultural da Educação Física: uma resposta aos dilemas da contemporaneidade ${ }^{1}$
}

\begin{abstract}
Resumo
Considerando a necessidade de oferecer respostas aos dilemas que afligem a sociedade atual, este artigo discute a importância da elaboração e implementação de um currículo que valorize a cultura corporal da comunidade e submeta o patrimônio de conhecimentos em circulação a uma análise crítica, desvelando as relações de poder que situam determinadas brincadeiras, danças, lutas, ginásticas e esportes como legítimos em detrimento de outros. Práticas como o funk, o rap, o skate, o parkour, o hip hop, o carrinho de rolimã, o baralho, o maculelê e a capoeira podem ser tematizadas na escola, tendo em vista a realização de uma ação educativa atenta à formação de identidades democráticas. Assim, ressalta-se o trabalho com a linguagem corporal como relevante ponto de partida para a compreensão da sociedade mais ampla. O que se pretende é, enfim, situar a instituição educativa como lócus da construção de uma postura aberta ao diálogo com as diferenças, aspecto cada vez mais relevante quando se considera a característica multicultural da contemporaneidade.
\end{abstract}

Palavras-chave: Educação Física - Estudo e Ensino; Currículo; Globalização; Neoliberalismo.

\author{
Marcos Garcia Neira \\ Doutor em Educação pela \\ Universidade de São Paulo - USP \\ - Brasil \\ mgneira@usp.br
}

\begin{abstract}
Para citar este artigo:
NEIRA, Marcos Garcia. O currículo cultural da Educação Física: uma resposta aos dilemas da contemporaneidade. Revista Linhas. Florianópolis, v. 16, n. 31, p. 276 - 304, maio/ago. 2015.
\end{abstract}

DOI: $10.5965 / 1984723816312015276$

http://dx.doi.org/10.5965/1984723816312015276

${ }^{1}$ Pesquisa realizada mediante financiamento da FAPESP. 


\title{
Everybody is a little sociologist, just as everybody is a little doctor: or why is sociology the best discipline in school
}

\begin{abstract}
Considering the need to providing answers to the dilemmas that afflict today's society, the lecture will discuss the importance of developing and implementing a curriculum that enhances the body culture of the community and submit the patrimony of knowledge in course to critical analysis, revealing relations power which position certain games, dances, wrestling, gymnastics and sports as legitimate rather than others. Practices such as funk, rap, skateboarding, parkour, hip hop, "carrinho de rolimã", deck cards, the "maculelê" and "capoeira" can be themed in school, with a view to carrying out an educational attempt to the construction of democratic identities. Therefore, it emphasizes working with body language as relevant starting point for understanding the broader society. The aim is ultimately to position the educational institution as a locus of building an open attitude to dialogue with the differences, an increasingly relevant aspect when considering the multicultural characteristic of contemporary.
\end{abstract}

Keywords: Physical Education - Study and Teaching; Culture; Curriculum; Globalization; Neoliberalism. 
A compreensão do atual contexto político, econômico e social e seus reflexos sobre a elaboração de propostas curriculares da Educação Física passa pela análise de dois fenômenos profundamente entrelaçados: o neoliberalismo e a globalização.

O termo neoliberalismo pode ser entendido como um conjunto particular de receitas econômicas e programas políticos que tiveram seu início nos anos 1970, inspirados nas obras de Milton Friedman e Friedrich Hayek e que desencadearam modificações nas relações institucionais entre o mercado e o Estado e entre as empresas e os mercados, definindo o processo que refletiu uma transformação estrutural na história do capitalismo (THERBORN, 1995).

O neoliberalismo é o novo caráter do velho capitalismo, pois aponta para uma economia regida pela mão invisível do mercado. O capitalismo transforma tudo em mercadoria, bens e serviços, e é reforçado pelo neoliberalismo através da mercantilização dos serviços essenciais, como os sistemas de saúde e educação, fornecimento de água e energia, sem poupar os bens simbólicos. (BETTO, 2010).

A compreensão do modelo neoliberal passa, entre outras coisas, por uma análise cuidadosa em torno das políticas instrumentalizadas nos anos 1980, quer por Ronald Reagan, nos Estados Unidos, quer por Margaret Thatcher, no Reino Unido. Usufruindo de um contexto internacional e nacional "privilegiado", a um e a outro se deve a gradual implementação das políticas econômicas e culturais. Um dos críticos, Apple (2003), descreve o neoliberalismo como um poderoso bloco de/no poder ${ }^{2}$, que muito tem contribuído, não propriamente para a crise em vários setores da sociedade, com especial destaque para a educação, mas sobretudo para a colocação do Estado como réu dessa crise.

Como princípio, o neoliberalismo defende que o mercado é o único instrumento eficaz para regular os interesses e as relações sociais, sendo o setor público o principal responsável pela crise atual. Os seus representantes procuram mostrar que o Estado é ineficiente e, por outro lado, o mercado e o setor privado são sinônimos de eficiência, qualidade e equidade.

\footnotetext{
${ }^{2}$ Adotamos a concepção de Michel Foucault, para quem o poder opera como uma rede e não se situa numa coisa ou lugar específico, mas que circula em todas as direções.
} 
Os neoliberais apontam também outros culpados pela crise - os sindicatos. A existência de sindicatos fortes e organizados que defendem interesses gerais e a construção de direitos sociais é, na perspectiva neoliberal, um entrave ao desenvolvimento de mecanismos de competição individual que garantam o progresso social.

Na sua explicação da crise, os neoliberais apontam a ineficácia do Estado no gerenciamento das políticas públicas. Afirmam que a democracia é um sistema político que permite aos indivíduos desenvolver uma capacidade de livre escolha, posicionando o mercado como o local que potencializa essa capacidade individual. Segundo tais premissas, o êxito é alcançado somente com o mérito individual e é o esforço de cada pessoa que a consagra como vencedora. Ocorre que vencer, em uma sociedade globalizada como a nossa, é algo cada vez mais raro.

A globalização consiste na difusão por todo o planeta de corporações transnacionais que assumem papéis de destaque na economia e no controle do capital. Como consequência, vêm ocorrendo mudanças nas relações de produção, enfraquecendo o Estado e minando a capacidade das nações mais antigas e tradicionais, além das sociedades emergentes, estabelecerem seus modos de ser ou controlar seu ritmo de desenvolvimento (NUNES, 2011).

Na contemporaneidade, pondera o autor, os meios de produção, circulação e intercâmbio cultural se estendem por todos os cantos do globo, expandindo uma infinita quantidade de informações graças à intensa revolução tecnológica. Como efeito, os meios de comunicação de massa expõem ininterruptamente modos e comportamentos diversificados, colocando todos frente às novas formas de compreender o ser humano, a história e a sociedade. Ao mesmo tempo em que tudo isso elimina a distância e o tempo e torna o mundo mais próximo, permite ações com intenções de homogeneizá-lo, e, assim, ampliam-se e diversificam-se as tentativas e as formas de regulação dos comportamentos dos indivíduos.

Os processos de globalização crescente geram uma série de modificações decisivas em escala planetária com a consolidação de dinâmicas mundiais de intercâmbio de imagens, pessoas e ideias. A economia neoliberal de mercado globalizado e o ciberespaço marcam os parâmetros do mundo atual do mesmo modo que a expansão 
colonial europeia e a penetração do capitalismo desafiaram as fronteiras geográficas e culturais do mundo ocidental no final do século XIX. A reestruturação da economia mundial, somada ao impacto dos meios de comunicação e à generalização do acesso à informação, desencadeou tendências globais com forças complementares, mas também contraditórias.

Na visão de García Canclini (2008), ao mesmo tempo em que coincide com a expansão dos mercados, a potencialidade econômica das sociedades e a globalização estreitam também a capacidade de ação dos Estados nacionais, dos partidos, dos sindicatos e políticos clássicos. Empregando a ideologia da abertura comercial e da desregulação da economia, o que surgiu foi um novo e precário mundo do trabalho.

A globalização das indústrias culturais em nível mundial fomentou a homogeneização do consumo e da cultura, ultrapassando fronteiras nacionais cuja identidade e esfera de atuação estão em permanente processo de redefinição nos espaços territoriais onde os limites geográficos nacionais se diluem na constituição de mercados globais. Produtos culturais como a música, o cinema, a publicidade ou as novelas e seriados televisivos configuram os referentes audiovisuais das novas gerações, que os consomem em grande medida, para além das fronteiras nacionais.

García Canclini (2008) explica que a globalização exige o lucro em todas as suas atividades; impõe a uniformização dos seres humanos, em que todos devem ser iguais e vestir-se da mesma forma; e impõe normas de comportamento, valores morais, ideologias e padrões estéticos e éticos. É importante para a globalização do lucro, destruir as culturas nacionais, bem como as culturas locais a qualquer custo, nem que para isso milhares de pessoas agonizem. Ao destruir suas culturas, destroem as próprias identidades.

A relativa unificação globalizada dos mercados não se sente perturbada pela existência de diferentes e desiguais: uma prova é o enfraquecimento destes termos e sua substituição por estes outros, inclusão e exclusão. $O$ que significa o predomínio deste vocabulário? A sociedade, antes concebida em termos de estratos e níveis, ou distinguindo-se segundo identidades étnicas ou nacionais, agora é pensada com a metáfora da rede. Os incluídos são os que estão conectados; os outros são excluídos, os que veem rompidos seus vínculos ao ficar sem trabalho, sem casa, sem conexão. (GARCÍA CANCLINI, 2009, p. 92) 
Em consequência, inclusão e exclusão constituem-se atualmente em elementoschave nas políticas de identidade, delimitadas especificamente a partir das dinâmicas identitárias. Nesse sentido, o consumo de produtos culturais passou a ser fundamental na criação de mecanismos que regulam a integração ou a exclusão dos membros de uma comunidade. A globalização dos alimentos, música, esportes, formas de lazer, programas de televisão e demais produtos culturais fomentam o espelhamento da construção artificial de uma "comunidade imaginária" em nível global e de referenciais culturais aparentemente universais no marco de um projeto econômico único em um mundo globalizado de recursos econômicos e culturais desiguais (ANDERSON, 1993). O desenvolvimento da ideia de civilização universal vinculada ao conceito de nação viabiliza a argumentação de que o neoliberalismo e o ciberespaço estão orientando o processo de construção de um ideário cultural universal a nível planetário.

\section{Reflexos na educação e na Educação Física}

No projeto neoliberal, a educação assume um papel estratégico com duas dimensões principais com vistas a servir aos propósitos empresariais e industriais. De um lado, a reestruturação social buscada pelos ideólogos neoliberais pretende atrelar a educação institucionalizada aos objetivos estreitos de preparação para o trabalho. Tratase de fazer com que as escolas preparem melhor seus alunos e alunas para a competitividade do mercado nacional e internacional. Para isso, é fundamental abortar qualquer modelo de pedagogia que invista na discussão do social e do político e concentrar esforços na eficiência, eficácia, aquisição e desenvolvimento de conhecimentos com potencial de aplicabilidade. Além disso, a escola neoliberal deve reforçar os discursos do individualismo e da afirmação de uma identidade baseada no mercado, convertendo produção cultural em mercadoria de consumo. De outro, é importante, também, utilizar a educação como veículo de transmissão de ideias que proclamam as excelências do livre mercado e da livre iniciativa como condições essenciais para a garantia do funcionamento estável da sociedade do século XXI. 
Trata-se de um esforço de alteração do currículo não apenas com o objetivo de dirigi-lo para uma capacitação estreita de mão de obra, mas também, preparar os estudantes para aceitar os postulados do credo neoliberal. Frente à agressividade dessa intenção, a encampação empresarial do setor público mina os discursos de responsabilidade social e defesa dos bens públicos, levando a crer que o mercado deva assumir as rédeas do processo. A pedagogia neoliberal ensina aos estudantes que as formas de desregulação da economia e as contribuições tecnológicas, científicas e culturais em circulação, logo, a serviço do livre mercado, consistem nas melhores alternativas para a sociedade global.

É em meio a esse contexto que a base epistemológica oriunda da psicologia cognitivista herdada das reformas do ensino na Europa e toda uma nomenclatura específica e convergente com os pressupostos do cidadão empreendedor almejado pelo neoliberalismo foram revigoradas. Expressões como "desenvolvimento de competências para o exercício pleno da cidadania e orientação para o mundo do trabalho" vieram acompanhadas de uma cisão no planejamento de ensino, objetivando isoladamente o alcance de determinadas expectativas por meio da aprendizagem de conteúdos conceituais, procedimentais e atitudinais. Com esse enfoque, os docentes passaram a organizar suas intervenções no formato de sequências didáticas baseadas na resolução de situações-problema, tendo em vista a aprendizagem dos conteúdos previstos. As ações didáticas decorrentes, embora disfarçadas com roupagem democrática, em muito se assemelham às anteriores preocupações com a aquisição de determinados conhecimentos universais e aplicáveis, estipulados verticalmente, fato que permite classificar tal pedagogia como alinhada à vertente tecnicista.

No campo educativo, Gentili (1996) afirma a necessidade de compreensão do neoliberalismo como um complexo processo de construção hegemônica, através de estratégias culturais que promovem novas construções de significados por meio de reformas concretas nos aspectos econômico, político, jurídico e educacional. Denunciando a crise de eficiência dos sistemas educacionais, o discurso neoliberal contém proposições políticas que visam reorientar também as reformas educacionais nas sociedades contemporâneas. 
A crise das instituições escolares é produto, segundo este enfoque, da expansão desordenada e "anárquica" que o sistema educacional vem sofrendo nos últimos anos. Trata-se fundamentalmente de uma crise de qualidade decorrente da improdutividade que caracteriza as práticas pedagógicas e a gestão administrativa da grande maioria dos estabelecimentos escolares. (GENTILI, 1996, p. 04)

Portanto, no discurso neoliberal está posto o caráter ineficiente do Estado para a administração das políticas públicas educacionais, cuja centralização e intervenção estatal só dificultam a qualificação do sistema educativo. Apresenta-se então, um novo enfoque gerencial que busca a qualidade do sistema e a ampliação da sua eficiência e produtividade que, obrigatoriamente, atravessa a qualificação dos professores, das escolas e a melhor distribuição dos recursos internos. Para o neoliberalismo, os sistemas educacionais enfrentam uma crise, não de democratização, mas uma crise de gestão, pois o sistema é mal administrado, e isso é o que possibilita o alto índice de analfabetismo funcional, a evasão escolar e a repetência.

O neoliberalismo transpôs a noção de qualidade total do campo empresarial para o educacional, transferindo a educação da esfera política para a esfera de mercado. Obviamente, esforça-se para camuflar o fato de que "qualidade total é inapelavelmente particular, interessada e politicamente enviesada" e a educação é vista "a partir de uma ótica econômica, pragmática, gerencial e administrativa” (SILVA, 1996, p. 120).

Para o neoliberalismo, a função social da escola passa a ser a transmissão de habilidades e competências ao aluno para que este possa instrumentalizar-se e inserir-se competitivamente no mundo do trabalho. Nesse contexto, é preciso estabelecer mecanismos de controle e avaliação da qualidade, tanto do ponto de vista macro da educação - órgãos responsáveis pelas políticas públicas -, quanto do ponto de vista micro - das instituições escolares. Na visão neoliberal, é necessário articular e subordinar a produção escolar às necessidades estabelecidas pelo mercado de trabalho.

Para Gentili (1996), o Estado neoliberal criou estratégias que contribuem para a implementação de sua ideologia: 
O neoliberalismo formula um conceito específico de qualidade, decorrente das práticas empresariais e transferido, sem mediações, para o campo educacional. As instituições escolares devem ser pensadas e avaliadas (isto é, devem ser julgados seus resultados), como se fossem empresas produtivas. Produz-se nelas um tipo específico de mercadoria (o conhecimento, o aluno escolarizado, o currículo) e, consequentemente, suas práticas devem estar submetidas aos mesmos critérios de avaliação que se aplicam em toda empresa dinâmica, eficiente e flexível. Se os sistemas de Total Quality Control (TQC) têm demonstrado um êxito comprovado no mundo dos negócios, deverão produzir os mesmos efeitos produtivos no campo educacional. (p. 25)

Ao se concentrar em técnicas e procedimentos de medição, em finalidades e objetivos educacionais definidos com base nos comportamentos a serem desenvolvidos, o ideário da Qualidade Total tende a fixar identidades hegemônicas como norma (SILVA, 1996).

Nessa lógica, as instituições de ensino devem ter clareza do que ensinam e dos resultados alcançados, o que torna necessário desenvolver mecanismos e políticas para aferi-los. É preciso saber se as escolas são empresas produtivas, pois o receituário neoliberal possui um conceito próprio e específico de qualidade. Não é por acaso que, nos últimos anos, tanto os sistemas públicos quanto privados engajaram-se na elaboração de propostas curriculares e no desenvolvimento de procedimentos avaliativos.

É impossível desvincular a forma como essas ações têm sido implementadas da ideologia incutida no discurso neoliberal. Tudo leva a crer que a implementação da política curricular e avaliativa relaciona-se com o modelo empresarial, pois o que se busca é a definição do que deve ser ensinado e a mensuração do rendimento.

Na perspectiva de Apple (2003), o neoliberalismo mostra-se favorável à cultura centralizada, ao controle sobre o saber, ao currículo nacional, ou seja, procura defender a todo custo uma cultura comum. O autor alerta que o sucesso do neoliberalismo encontrase na dependência da implementação de uma série de políticas neoconservadoras no Estado, de modo a sintonizá-lo com as formas de pensar dos setores dominantes, o que implica na garantia de estabelecer padrões educacionais a serem alcançados e de testes efetivos para mensurá-los. 
O Conselho Nacional de Educação, em 1998, normatizou a indicação de conteúdos mínimos obrigatórios das áreas de conhecimento, através da instituição das Diretrizes Curriculares Nacionais, com o objetivo de assegurar nas propostas curriculares uma formação básica comum. Para isso, implementou uma Base Nacional Comum obrigatória e uma Parte Diversificada a todo sistema educacional do país.

É nesse contexto, que pela primeira vez na história educacional do Brasil, o Estado faz publicar um corpo de documentos que pretendem fornecer os subsídios necessários para o desenvolvimento dos currículos escolares, os denominados Parâmetros Curriculares Nacionais (BRASIL, 1997, 1998 e 1999).

Ao analisar o modo como se deu o processo de elaboração dos documentos, Caparroz (2003) é enfático:

[...] o Ministério da Educação não convocou ou convidou a área de educação física para participar da construção dos PCN e, sim, uma parcela desta, restrita ao meio acadêmico, que estava mais em consonância com os pressupostos epistemológicos que sustentaram os PCN e com o ideário neoliberal da política educacional. (p. 328)

Quanto à forma de distribuição do documento Darido (2001), assim se posiciona:

A intenção da Secretaria de Ensino Fundamental do MEC era a de que todos os professores da rede pública do país recebessem o conjunto de documentos, o que acabou não ocorrendo. Como os documentos foram enviados para as escolas, e não para as residências dos docentes, muitos acabaram ficando sem os exemplares. $O$ número exato de professores que receberam os documentos não foi divulgado, de toda forma, muitos foram agraciados. (p. 28)

Talvez, a versão impressa não tenha chegado à maioria dos docentes que atuava nas escolas à época em que esses estudos foram realizados. Todavia, o tempo ensinou que menosprezar o poder de disseminação dos princípios e orientações contidos na proposta federal é um equívoco. A pesquisa de Gramorelli e Neira (2009) revelou que a ideologia neoliberal embutida nos PCN encontra-se à disposição em inúmeros outros produtos culturais aos quais os professores têm maior acesso: matérias das revistas pedagógicas de grande circulação, a presença marcante nas bibliografias dos concursos 
públicos para ingresso nos quadros do magistério e nas disciplinas dos cursos de formação inicial, cursos de formação contínua promovidos por diversas instituições, ações formativas implementadas pelas secretarias estaduais e municipais, livros didáticos e paradidáticos desenvolvidos com os pressupostos dos documentos etc.

Constata-se que o projeto neoliberal tem ao seu lado um poderoso instrumento para conquista da hegemonia, qual seja, a utilização dos meios de comunicação de massa a seu favor. Artimanha que se traduz não apenas no controle da mídia, mas também, na transformação da população escolar em mercado-alvo para os produtos veiculados pela cultura de massa e na sua utilização como canal de transmissão da doutrina neoliberal (SILVA, 1996).

A rede neoliberal construída para capturar o professor é de tal monta que termina por exercer grande influência e validar uma determinada visão como a melhor. Caparroz (2003) menciona os riscos de tal socialização:

[..] que condições o professorado tem para se apropriar e dominar criticamente o que é produzido academicamente? Como ele se relaciona com esta produção e com as orientações normativo-curriculares para construir sua autoridade e autoria docente? O professorado tem que grau de autonomia (ou é submisso) em relação a estas? (p. 328)

A onda neoliberal e os efeitos da globalização atuam em diversas frentes e a Educação Física, enquanto área de conhecimento que abrange não somente a dimensão pedagógica escolar, como também outros campos de intervenção, sofreu um grande impacto devido às características do seu objeto, ou seja, as práticas corporais sóciohistoricamente produzidas e reproduzidas.

O discurso neoliberal contagiou a área de uma forma muito interessante, chegando inclusive a influenciar e determinar o surgimento de instituições, modalidades, eventos e, como consequência, um enorme mercado de consumo estimulado pela mídia por meio de programas específicos, publicidade, socialização de formas de comportamento e, principalmente, modelos de estética corporal. 
Tomada pelos ventos da primazia da aparência, da cultura do desejo e do consumo e da busca da rentabilidade em qualquer produto, a ideologia neoliberal afirma a satisfação de mostrar uma juventude atemporal, possuidora de um modelo de corpo que alguns desejam ter e faz com que outros lamentem os tempos idos. O corpo humano almejado para o século XXI é depositário da liberdade imposta pela religião ao longo de séculos, do prazer sem limites e da vitalidade da juventude. O comércio do corpo jovem invadiu as etapas mais precoces da vida para minimizar o desespero de ver escapar, de forma acelerada, a referência idealizada. O corpo jovem, com todos os atributos subjetivos que o acompanham, transformou-se no objeto preferido do empreendimento neoliberal, pois, não se trata de algo que possa simplesmente ser adquirido de uma vez por todas. É necessário mantê-lo, cuidá-lo, cultivá-lo ao longo da vida e, obviamente, o currículo escolar terá um papel importante nesse processo de convencimento ao socializar esse mesmo ideal pela valorização de conteúdos relativos à nutrição, exercício, vida saudável etc. O interesse na construção desses valores, portanto, passa bem distante de qualquer política pública direcionada à saúde ou do bem-estar da população.

Para esclarecer esse fenômeno e suas influências ontológicas, Sant'Anna (2001) recorre às seguintes hipóteses: 1) os avanços científicos possibilitaram a tudo explicar, portanto, é o corpo o último território a ser explorado. Notam-se, por exemplo, a ânsia pelas descobertas da Engenharia Genética, pelo mapeamento do DNA, pela utilização das células-tronco na regeneração ou mesmo, construção de órgãos etc.; 2) as restrições de outrora desmancharam-se diante da nova configuração social. Embora livres dos grilhões da moralidade, homens e mulheres têm suas ações permanentemente vigiadas por um sem número de câmeras e olhares. O corpo é visto, então, como sua única e verdadeira posse, como campo de exercícios da liberdade individual; e 3) A tendência atual em considerar o corpo como aquilo que é mais próximo da identidade de um ser, constituindo a representação de que é por meio dele que se mostra o melhor de si, o que faz emergir uma extrema preocupação com a aparência pessoal, ou seja, "sou aquilo que pareço ser".

A intensa socialização desses códigos, bem como determinadas concepções de "autonomia" e "cuidado individual com a saúde", fizeram reforçar o individualismo e o discurso do acúmulo de benefícios como resultado do esforço pessoal. Esse contexto, 
bastante fértil na passagem para o século XXI, estabeleceu como paradigma o apelo neoliberal de uma "vida saudável", conferido por meio de iniciativas individuais que aludem a um determinado estilo de vida muito mais próximo dos setores economicamente privilegiados. Afinal, quem pode adotar hábitos em consonância com os referenciais propagados pelo discurso neoliberal da saúde? Sob essas influências e ressuscitando o discurso biológico na área, determinados setores acadêmicos e oficiais passaram a sugerir um modelo curricular para a Educação Física com vistas a informar, mudar atitudes e promover a prática sistemática de exercícios físicos com a finalidade de favorecer um estilo de vida ativo, ou seja, alcançar e manter o corpo jovem idealizado. Os conteúdos privilegiados focalizam a distribuição ao longo dos anos escolares dos conceitos oriundos da Fisiologia, Anatomia, Medidas de Avaliação, Treinamento Desportivo e Nutrição, e a execução de atividades físicas não excludentes, basicamente pautadas na prática de exercícios físicos com bases científicas.

Tal vertente pretende propiciar a aquisição de conhecimentos alusivos à importância da atividade física voltada para a melhoria da aptidão; estimular atitudes positivas com relação aos exercícios físicos; estabelecer, como comportamento universal, a prática regular de atividades que possam ter continuidade após os anos escolares; e promover independência na escolha de programas de atividades físicas relacionados à saúde. A avaliação baseada na aprendizagem de conceitos relacionados ao vínculo entre atividade física e saúde, bem como à execução dos exercícios propostos, deve enfatizar todo o processo, com o objetivo de favorecer a autoestima dos alunos. A finalidade mal escondida desse dispositivo segue a cartilha neoliberal ao colocar sob o mesmo manto a conquista de uma determinada aparência física e o desejado aceite da sociedade.

Uma análise mais cuidadosa, tanto dos meios empregados quanto das promessas feitas por esse currículo permite verificar não só o neo-higienismo camuflado sob o discurso do "sentir-se bem", como também, as intenções de uma sociedade que procura apropriar-se ao máximo dos parcos recursos da população (físicos e financeiros) e, portanto, necessita de um povo bem treinado e condicionado, sem que sejam necessários muitos investimentos sociais tais como programas de saúde coletiva, oportunidades de lazer, melhoria nas condições de habitação e transporte etc. 
Por meio da intensa difusão de códigos, o currículo baseado na educação para a saúde, com o apoio dos meios de comunicação, inculca formas de comportamento que reverterão em gigantescos lucros para os setores privilegiados da sociedade. Afinal, quem mais se beneficia com o prolongamento do tempo de atividade profissional sem alentar esperanças de aposentadoria, com a difusão da ginástica laboral, da política de redução de hábitos "pouco saudáveis", da condenação de certos alimentos próprios dos grupos culturais que dispõem de menor poder, entre outras facetas que caracterizam o estilo de vida saudável?

A lógica neoliberal do livre mercado arrasa qualquer tentativa de regulação e rompe não apenas as barreiras (artificiais) econômicas ou continentais, mas também, as formas de organização política e social de distintas comunidades, restringindo o ser ao ter (um certo desenho corporal, inclusive). Do mesmo modo, desmobiliza, por meio de seus discursos de benefício do capital, qualquer ação política que conteste o inevitável aumento da instabilidade no emprego, da precariedade dos serviços públicos e até do desapego às questões político-partidárias, associacionistas e sindicais. Ou seja, desqualifica qualquer forma de contestação aos seus princípios.

\section{Alternativa}

A contrapartida desta dinâmica homogeneizadora das últimas décadas é, paradoxalmente, o surgimento de uma tendência paralela de fragmentação que se manifesta em uma reivindicação da diversidade. Diante dos projetos culturais de homogeneização em torno de uma norma monocultural hegemônica, a afirmação das diferenças se expressa em termos plurais a partir de distintas instâncias religiosas, políticas, estéticas, étnicas ou de gênero. Dessa perspectiva, a diversidade cultural nada mais é que a expressão dinâmica de significados construídos de forma diversa em contextos específicos. É por isso que as políticas de identidade são a chave no processo de construção de identidades coletivas que partem do reconhecimento da diversidade.

Segundo McLaren e Giroux (2000), novos movimentos sociais surgidos a partir da década de 1970 e várias políticas atuais se sustentam a partir do paradigma da diferença e 
do desenvolvimento de políticas de identidade, refletindo no incentivo à igualdade de oportunidades ou ações afirmativas para minorias, mulheres, migrantes, idosos, crianças e afrodescendentes nos últimos anos. Os marcos referenciais da diversidade cultural, a partir da construção de identidades coletivas diferentes e, às vezes contestadas, converteram-se em um dos eixos das dinâmicas sociopolíticas do mundo na atualidade.

Os significados das diferenças culturais se constroem conforme as circunstâncias políticas, sociais e culturais. Com impactos desiguais em função do marco da cultura política e civil, história e reconhecimento de diferenças existentes em cada sociedade, as diferenças se constituiriam a partir dos eixos de Estado-nação, religião e etnia. McLaren (2000) expande esse grupo para todos aqueles que em determinados espaços sociais compõem as minorias e grupos subjugados que se encontram desprovidos de poder. Em todos os casos, as representações culturais que envolvem o outro incorporam essa dinâmica de construção da identidade a partir das chamadas de inclusão e exclusão da comunidade imaginária que sustenta a identidade assumida (ANDERSON, 1993). A imagem do outro se consolida a partir da representação, mediante múltiplos dispositivos simbólicos cujos registros não somente enunciam, como também reafirmam as diferenças, embora algumas colocações veiculadas pelo senso comum apresentem as identidades como fruto da construção dos próprios grupos de migrantes, mulheres, homossexuais, afrodescendentes etc.

A descolonização e os processos culturais que emergiram no seu interior questionam há décadas a primazia do modelo hegemônico ocidental do homem branco, macho, europeu, heterossexual e cristão como o sujeito único do pensamento político universal. Ao questionar a autoridade do pensamento masculino ocidental, os movimentos sociais dos direitos civis, as feministas, os ambientalistas, os sem-terra, os sem-teto, o poder negro, a comunidade gay, os movimentos de descolonização, além de outras forças sociais destacam a complexidade das relações hierárquicas de poder que podem sustentar-se na suposta pluralidade das diferenças.

O desafio do século XXI é o pleno exercício dos direitos humanos com a garantia do princípio da igualdade a partir do reconhecimento da diversidade, ou seja, a equidade. Nessa perspectiva, Sousa Santos (1997) convida a refletir sobre o exercício dos direitos humanos universais no mundo globalizado e a implicação do conceito de cidadania em 
sociedades nas quais atuam poderosos mecanismos excludentes postos em ação por setores crescentes, vitimando parcelas cada vez maiores de minorias sem direito à cidadania.

O ponto a ser ressaltado no presente momento é o a visibilidade crescente de diferentes identidades em diversos contextos que até pouco tempo procuravam preservar-se à mistura. O reconhecimento da diversidade existente e a atuação de forma plural a partir da constatação das diferenças de classe social, etnia, idade, local de moradia, gênero, religião ou trajetória escolar permitem abordar a complexidade social e cultural da sociedade atual. Ao evitar pressupostos universalistas da experiência humana, abrem-se horizontes às identidades sociais e culturais particulares. O embate com a falsa ideia de homogeneização elaborada pelo mercado facilita a identificação, em cada momento e contexto concreto, das iniciativas de subjetividade coletiva que surgem a partir do reconhecimento de identidades específicas. Nesse sentido, a eclosão de propostas que levam em conta a necessidade de construção de sociedades mais plurais e democráticas, "corrigindo injustiças" contra identidades específicas, tem gerado modificações nas políticas educacionais.

A institucionalização do discurso do direito à educação escolar e à igualdade de oportunidades de acesso à escola, ao lado de outras políticas públicas, pretende responder positivamente ao multiculturalismo crescente. Muito embora a expansão do atendimento à população seja um aspecto louvável, Leite (2001) e Formosinho (2007) denunciam que a progressão geométrica do número de vagas representou tão somente a reprodução do mesmo ensino para todos indistintamente. Na ótica de García Canclini (2009), esse processo é decorrente do utópico projeto da modernidade ilustrada, obviamente não realizado, que pretendia garantir que as manifestações julgadas mais valiosas fossem conhecidas e compreendidas por todas as sociedades e todos os setores.

A nova demanda social repercutiu sobre a população escolar, fazendo avolumar-se a contradição já existente entre a cultura historicamente privilegiada pelo currículo e as culturas dos alunos. A situação ganhou maior visibilidade a partir do ingresso na escola dos filhos dos grupos até então dela excluídos. Stoer e Cortesão (1999) acentuam que o aumento do número de alunos tem sido acompanhado de um acréscimo da diversidade nas instituições escolares. Públicos antes não escolarizados, de distintas origens sociais e 
culturais, começam progressivamente a constituir-se como uma parcela importante do corpo discente. Silva (2000) constata que a ampliação da heterogeneidade da população escolar desencadeou um problema curricular concretizado no constante enfrentamento com o outro. "O outro é o outro gênero, o outro é a cor diferente, o outro é a outra sexualidade, o outro é a outra raça, o outro é a outra nacionalidade, o outro é o corpo diferente" (SILVA, 2000, p. 97). Enfim, o outro, agora, está ao lado.

Procurando minimizar o problema, ao menos em caráter oficial, a política curricular brasileira vem atentando às questões da diversidade cultural. Para além da produção de documentos norteadores (BRASIL, 2007a), a legislação reivindicou alterações curriculares significativas, tendo em vista o reconhecimento do patrimônio cultural de grupos minoritários (BRASIL, 2007b); e um amplo conjunto de iniciativas ${ }^{3}$ quer seja na esfera municipal, estadual ou federal -, gradativamente vem sendo posto em prática. O estopim dessas medidas pode ser atribuído ao confronto entre a realidade desajustada dos currículos monoculturais das escolas e os efeitos do progressivo multiculturalismo da sociedade. O desajuste, aliado aos ideais democráticos que passaram a orientar as políticas educativas e que assumiram o princípio da "escola para todos", evidenciou a necessidade de analisar o currículo e nele intervir diante das condições que oferece aos novos estudantes. De fato, quando a educação escolar é considerada um bem público, justifica-se a exigência de que todos sejam seus beneficiários e, se não forem todos, que se questione a razão de tal improcedência.

Caracterizando a situação do ponto de vista das práticas educativas desejadas, pode-se dizer que a ideologia democrática começou a apontar para a necessidade de se desenvolver situações pedagógicas que, em substituição à cultura do silêncio, fizessem ecoar as vozes das minorias (GIROUX, 2006). Ao mesmo tempo, o princípio da igualdade de oportunidades veiculado em termos não só de acesso à educação escolar, mas também de sucesso, tornou evidente que já não basta a matrícula escolar de crianças, jovens e adultos provenientes de grupos sociais, culturais e econômicos diversos, é necessário intervir de modo a democratizar as condições de sucesso.

\footnotetext{
3 Dentre as iniciativas mais comuns, destacam-se o transporte escolar subsidiado, refeições, material escolar, programas nacional e estaduais do livro didático, políticas de educação inclusiva etc.
} 
A alternativa vislumbrada por Moreira (2001), Pereira (2004) e Santos (2007), ao menos por enquanto, é a inserção e problematização no currículo daqueles conhecimentos advindos das culturas subordinadas, a chamada educação multicultural.

Ao analisar o caráter multicultural de nossa sociedade em processo de globalização e como as questões das diferenças de classe social, gênero, etnia, orientação sexual, cultura e religião se expressam em diferentes contextos sociais, Moreira (2001) refere-se à educação multicultural como a "sensibilidade para pluralidade de valores e universos culturais no interior de cada sociedade e entre diferentes sociedades" (MOREIRA, 2001, p. 66). Ângelo (2002, p. 39) entende que a educação multicultural "pode ser um dos instrumentos pedagógicos sociais para construir as relações interculturais baseadas no diálogo entre as culturas". Por sua vez, Willinsky (2002) reivindica uma educação multicultural que conteste as linhas divisórias e a importância da diferença, que não aceite as divisões entre os seres humanos como um fato da natureza, mas como uma categoria teórica produzida por quem está no poder.

A educação em uma perspectiva multicultural crítica não só valoriza e reconhece as diferenças, como também assegura a diversidade cultural, superando processos discriminatórios, opressão, injustiça social e naturalização das diferenças, apontando focos de resistência e de construção da identidade cultural.

Ora, se quisermos corresponder às demandas da contemporaneidade e adotar a inclusão, justiça, diálogo, reconhecimento, diferença e equidade como princípios pedagógicos da Educação Física, temos que romper com o continuísmo que asfixia o componente, adotar a cultura corporal como objeto de estudo e, conforme defendemos anteriormente (NEIRA, 2006), desenvolver currículos multiculturalmente orientados.

Imbuídos da responsabilidade de encontrar novos caminhos, imersos no contexto escolar em diferentes momentos, um grupo de professores ${ }^{4}$ e colaboradores produziram situações de debate, construção, implementação e avaliação de uma proposta curricular que contempla a diversidade cultural corporal da comunidade escolar, visando à formação de identidades democráticas. Em alguns casos, mediante ações de formação contínua, os docentes revisaram, analisaram e procuraram hibridizar os currículos das

\footnotetext{
${ }^{4}$ Grupo de Pesquisas em Educação Física escolar da FEUSP (www.gpef.fe.usp.br).
} 
escolas que atendem representantes de comunidades marcadas pela diversidade, respeitando sua dignidade e identidade cultural e viabilizando uma participação mais efetiva na vida pública.

O entendimento de que as propostas curriculares da Educação Física contaminadas com o ideário neoliberal não coadunam com a função social da escola multicultural contemporânea foi o estopim para o esforço conjunto para a construção e o desenvolvimento de um currículo inspirado nos Estudos Culturais e no multiculturalismo crítico.

Esses campos teóricos não apontam nenhum caminho perfeccionista, salvacionista ou progressista, não se arrogam a pretensão de oferecer a interpretação mais coincidente com a realidade e, tampouco, "constituem uma doutrina geral sobre o que é 'bom ser', nem um corpo de princípios imutáveis do que é 'certo fazer'” (CORAZZA, 2001, p. 56). No campo curricular, não oferecem nenhuma proposta de modificação dos comportamentos ou sentimentos calcada em ideais regulatórios, contentam-se com problematizar a cultura em que vivemos e o tipo de subjetivação promovida pela experiência escolar.

A experiência acumulada pelos participantes do Grupo mostrou que "artistar" currículos implica necessariamente em atribuir outros significados para o planejamento, execução e avaliação da tarefa educacional. Ora, produzir um currículo nada mais é do que produzir cultura. Perante os posicionamentos dos professores participantes durante as reuniões ou seminários internos para discussão das práticas, notamos que os currículos que colocam em ação não estão escritos nos textos discutidos ou nos produtos das investigações.

Conforme o contexto escolar e comunitário, cada professor inventou alternativas metodológicas, elegeu temas diversos e produziu a sua novidade. A teoria, na prática, transformou-se. Mesmo artistando um currículo próprio, denominam-no "cultural” por

\footnotetext{
5 “Artistar é uma estética, uma ética e uma política a se inventar junto a uma educação que procura "o não sabido, o não olhado, o não pensado, o não sentido, o não dito." A pesquisa, o trabalho do professor com seus orientandos e alunos, dá-se nas zonas fronteiriças, na penumbra da cultura, nas tocas mais estranhas da linguagem. Como em todo desenvolvimento de uma arte, artistar a educação implica em entregar-se ao caos para extrair dali matérias para criações. Trata-se de "arriscar-se, assumir o risco da morte, que é estar viva/o, sem se considerar um produto acabado" (CORAZZA, 2002, p. 15).
} 
basearem-se nos compromissos políticos dos Estudos Culturais e pedagógicos do multiculturalismo crítico.

Mas o que se pode entender como currículo cultural da Educação Física?

Inspirando-se na teorização cultural, Silva (2007), reafirma o ideal de uma sociedade que considere prioritário o cumprimento do direito que todos os seres humanos têm de ter uma vida digna, ou seja, de ter uma vida em que sejam plenamente satisfeitas suas necessidades vitais, sociais e históricas. Nesse cenário, sinaliza o autor, a educação está estreitamente vinculada à construção de uma sociedade em que riqueza, recursos materiais e simbólicos e condições adequadas sejam mais bem distribuídos. A educação deve ser construída como um espaço público que promova essa possibilidade e como um local em que se forjem identidades sociais democráticas.

Um currículo de Educação Física comprometido com essa visão, denominada cultural, multicultural crítica ou intercultural, procura impedir a reprodução consciente ou inconsciente da ideologia dominante, presente, por exemplo, nas propostas que deixam de questionar as relações de poder que perpassam a produção e reprodução das práticas corporais (NEIRA, 2014). O currículo cultural tem como pressuposto básico a recorrência à política da diferença por meio da valorização das vozes daqueles que são quase sempre silenciados (GIROUX, 2008). Trata-se de um apelo para que se reconheça que nas escolas, assim como na sociedade, os significados são produzidos por experiências que precisam ser analisadas em seu sentido político-cultural mais amplo.

Um currículo cultural da Educação Física prestigia, desde seu planejamento, procedimentos democráticos para a decisão dos temas que serão estudados e das atividades de ensino. Valoriza a reflexão crítica sobre práticas sociais da cultura corporal do universo vivencial dos alunos para, em seguida, aprofundá-las e ampliá-las mediante o diálogo com outras vozes (NEIRA, 2009). No currículo cultural, a experiência escolar é um terreno aberto ao debate, ao encontro de culturas e à confluência da diversidade de práticas corporais dos variados grupos sociais. É um campo de disseminação de sentidos, de polissemia, de produção de identidades voltadas para a análise, interpretação, questionamento e diálogo entre e a partir das culturas.

O estudo de Canen e Oliveira (2002) demonstrou que o currículo cultural: 
[...] valoriza a diversidade e questiona a própria construção das diferenças e, por conseguinte, dos estereótipos e preconceitos contra aqueles percebidos como "diferentes" no seio de sociedades desiguais e excludentes. (CORAZZA, 2002, p. 61)

Os Estudos Culturais e o multiculturalismo crítico promovem as vozes dos professores, analisam criticamente as relações de poder entre as culturas e seus sujeitos, rompem com o preconceito de ideias sobre as condutas e decisões dos alunos e comparações entre eles e suas culturas, a hierarquização e dicotomização (global/local e científico/senso comum), valorizam as posturas reivindicatórias em oposição ao modelo neoliberal de formação da cidadania que exalta o consumidor; criticam a essencialização, o etnocentrismo e a naturalização do currículo fundamento pelo discurso tecnicista e o modelo de cultura universal desafiam a formação de uma identidade única que não distingue a pluralidade de identidades e diferenças dos sujeitos e valorizam as lutas pela equidade educacional (MOREIRA, 2001; CANEN, 2000; CANDAU, 2005).

Muito embora isso não aconteça somente na escolarização, mas também em muitas outras experiências, o currículo cultural promove entrecruzamentos culturais e superação de processos discriminatórios pela reflexão crítica e multicultural do professor. O que se espera é a organização e desenvolvimento de encontros letivos nos quais os alunos sejam convidados a refletir sobre a própria cultura corporal, o patrimônio disponível socialmente e a bagagem veiculada por outros grupos.

Nos dizeres de Mizukami (1986, p. 94), “a educação se dá, enquanto processo, em um contexto que deve necessariamente ser levado em consideração". A educação, segundo a autora, é uma pedagogia do conhecimento, e o diálogo a garantia desse ato de conhecimento. Sendo assim, o currículo cultural deve comprometer constantemente os alunos com a problemática de suas situações existenciais. Evidentemente, isso implica na busca permanente pela explicitação das possibilidades e limites oriundos da realidade sociopolítica, cultural e econômica enfrentada pelos cidadãos no seu cotidiano, que condiciona e determina a construção, permanência e transformação da cultura corporal.

O currículo cultural da Educação Física tenciona posicionar os estudantes como sujeitos da transformação social e contribuir com a construção de uma sociedade mais 
democrática e justa. Esse currículo prioriza a construção de práticas atentas à pluralidade de identidades dos alunos, assim como enxerga a escola como espaço-tempo multicultural de formação (CANDAU, 2003).

Consequentemente, a prática pedagógica deve articular-se ao contexto de vida comunitária; apresentar condições para que sejam experimentadas e interpretadas as formas como a cultura corporal é representada no cenário social; ressignificar as práticas corporais conforme as características do grupo; aprofundar os conhecimentos acerca do patrimônio cultural corporal; e ampliar os saberes dos alunos a respeito das temáticas estudadas (NEIRA, 2011).

Esse currículo cultural pretende fazer "falar", por meio do estudo das práticas corporais, a voz de várias culturas no tempo e no espaço, além de problematizar as relações de poder explícitas e implícitas. Nesse prisma, pode ser concebido como terreno de luta pela validação dos significados atribuídos às práticas corporais pelos diversos grupos, visando à ampliação ou conquista de espaços na sociedade.

Sob influência dos Estudos Culturais e do multiculturalismo crítico, o currículo cultural da Educação Física é concebido como espaço-tempo de encontro das culturas corporais, construção de identidades e diferenças, questões de discriminação e preconceitos étnicos, de gênero, orientação sexual, habilidade ou padrão corporal, entre outros; possibilita uma leitura dos grupos de pequena representação, hierarquizados pelos sistemas hegemônicos - econômico, político, social e cultural - diferenciados pelas suas atitudes e interesses; intenta identificar a opressão e a subalternização de culturas e sujeitos, erros históricos no processo de formação identitária dos negros, da mulher, dos homossexuais, dos pobres, dos deficientes e daqueles vistos como incapazes, molengas, fracos, lerdos etc. (CANDAU, 2005).

Cumpre também a função de expor as hipóteses ingênuas que normalmente permeiam as ressignificações sofridas por uma prática corporal qualquer. Se o que se pretende é formar cidadãos para uma sociedade menos desigual, como não debater as questões de gênero presentes na trajetória do futebol ou do voleibol? Ou as questões de classe e etnia presentes na trajetória do hip hop e do rap? Como não indagar as questões de classe, gênero, cultura e etnia incrustadas no percurso histórico das ginásticas? Kincheloe e Steinberg (2012) alertam que a carência de atividades que proporcionem a 
análise dos artefatos existentes fará persistir a cegueira cultural que impede o reconhecimento das relações sociais do mundo vivencial.

A pedagogia que caracteriza o currículo cultural dá visibilidade à gênese e ao desenvolvimento contextual das práticas corporais. Seguindo as recomendações de Torres Santomé (1998) e Giroux e Simon (2005), as revelações preparam o ambiente para a desconstrução dos significados implícitos nos discursos que desqualificam certas manifestações pertencentes à cultura popular. Quando o processo de construção das expressões pejorativas dirigidas à cultura corporal subjugada vem à tona, é possível tomar consciência de que certas danças, lutas, ginásticas, brincadeiras ou esportes são vistos a partir de estereótipos e das influências geradas pelas relações de poder. Comumente, o patrimônio pertencente aos grupos dominantes é exaltado enquanto as práticas oriundas dos grupos subordinados são desqualificadas. Apple (2003) explica que a desigualdade não é um simples preconceito ou fenômeno cultural, outrossim, baseia-se na forma pela qual certos grupos se localizam econômica e politicamente na sociedade.

Kincheloe e Steinberg (2012) recomendam que se desenterrem os conhecimentos subordinados, pois a história da subordinação foi propositadamente enterrada ou disfarçada. Seus conflitos e opressões foram perdidos sob uma estrutura teórica dominante, erradicada por uma triunfante história de ideias ou, talvez, seus conhecimentos tenham sido desqualificados e considerados primitivos, por não estarem à altura das definições dominantes do que se reconhece como científico, correto ou benéfico. As práticas corporais dos culturalmente diferentes coincidem com este último significado, já que a cultura dominante os considerou estranhos, curiosos, indignos de lógica, primitivos, exóticos e subalternos.

Basta verificar que, dentre a imensa quantidade de jogos de tabuleiro existentes, em sua maioria pertencentes às culturas subordinadas, é o xadrez, com suas atribuições cognitivistas, que ocupa um lugar de destaque no currículo escolar. Também é comum conferir significados pejorativos a algumas danças urbanas, a certos esportes radicais, à farra do boi, rinha de galos ou determinados jogos de cartas que se encontram entre as práticas corporais cujas histórias de disputas sociais foram "enterradas". O currículo cultural exorta a cultura dominante a interromper a supressão do papel do conflito na história e, para tanto, toma emprestada a genealogia arqueológica desenvolvida por 
Foucault (1981) para descrever o processo de recordar e incorporar as memórias dos conhecimentos subordinados, os conflitos vividos e as dimensões do poder que se revelam nas lutas atuais.

Mediante a especificação da natureza dos saberes e significados excluídos, o currículo cultural prepara os indivíduos para a luta estratégica entre o conhecimento subordinado e o conhecimento dominante. Esse é o princípio que rege uma pedagogia da política e uma política da pedagogia (SILVA, 1996). Se a insurreição dos conhecimentos subordinados já existe entre os oprimidos, não cabe aos intelectuais da cultura dominante teorizar sobre tais saberes visando convertê-los em existência curricular. Não é o professor de Educação Física quem deve descrever e relatar as práticas corporais dos subordinados, atribuindo-lhes, conforme lhe pareça, os significados para que os alunos os assimilem. O currículo cultural cria espaços e constrói as condições para que as vozes e as gestualidades subjugadas possam ser reconhecidas pelos estudantes.

A prática fundamentada na história do conhecimento subordinado começa pela denúncia das formas pelas quais as escolas se estruturam em torno de determinados silêncios e omissões. Uma observação atenta da arquitetura escolar permitirá constatar o silenciamento forçado de certas práticas corporais mediante a ausência total de espaços e condições para a criação e vivência de práticas para além das conhecidas brincadeiras, danças e modalidades esportivas dominantes. Quais escolas disponibilizam mais que uma quadra ou pátio para as aulas? Quais adquirem outros artefatos para além das bolas e redes? Como reagem os diversos sujeitos escolares quando o professor busca promover atividades de ensino em sala de aula, sala de vídeo, biblioteca, laboratório, sala de informática ou outros ambientes "menos convencionais"? Que empecilhos surgem quando o currículo quer contemplar bocha, jogo de damas, maculelê, lutas, danças indígenas ou de origem africana?

Na perspectiva cultural, os docentes estabelecem vínculos com as comunidades marginalizadas a fim de incorporar o conhecimento subordinado; mas não com os elementos exitosos dessas comunidades tal como são definidos pela cultura dominante e sim com uma variedade de grupos e subgrupos que convivem no seu interior. A valorização dos saberes de representantes dos diversos grupos que habitam cada comunidade proporciona ao currículo escolar uma diversidade de tradições, 
particularidades históricas, práticas sociais e culturas por vezes desacreditadas pela tradição escolar (NEIRA; NUNES, 2009).

Os educadores que atuam inspirados pelos valores do currículo cultural reescrevem diariamente e durante as aulas uma nova prática pedagógica de cunho democrático. McLaren (1997) ensina que essa redação inovadora leva à inclusão dos conhecimentos da cultura corporal dos grupos subordinados e a uma nova perspectiva dos olhares dos alunos sobre si próprios e sobre seu grupo, possibilitando uma prática em constante fluxo entre o local e o global, entre a comunidade e a sociedade mais ampla. No currículo cultural, os educadores medeiam o processo e fazem com que os alunos percebam os hibridismos e mestiçagens, tornando-se, eles próprios, pesquisadores do cotidiano.

Para Garcia (2001), ao situar no currículo os conhecimentos que os alunos trazem quando entram na escola e submetê-los à crítica enquanto elemento constitutivo da prática pedagógica, o professor os reconhece como sujeitos que possuem saberes legítimos, sujeitos capazes - capacidade revelada e reconhecida no já sabido, e capacidade potencial para se apropriar de novos conhecimentos que a escola pode e deve oferecer.

Com isso, tem-se não só a valorização identitária, como também a ampliação cultural e o reconhecimento das diferenças. Somente o diálogo cultural contribuirá para a construção do autoconceito positivo e do respeito ao outro, elementos indispensáveis a uma relação democrática. 


\section{Referências}

ANDERSON, Benedict. Las comunidades imaginárias. México: Fondo de Cultura Económica, 1993.

ÂNGELO, Francisca Novatino. A educação e a diversidade cultural. Cadernos de Educação Indígena, Barra dos Bugres, v. 1, n. 1, p. 34-40, 2002.

APPLE, Michael. Educando à direita: mercado, padrões, Deus e desigualdade. São Paulo: Cortez, 2003.

BETTO, Frei. O que é neoliberalismo. São Paulo. 07/04/2010 Disponivel >< http://www.sociologiapopular.com/2010/04/o-que-e-o-neoliberalismo-por-freibetto.html >. Acesso em 28/07/2015.

BRASIL. Ministério da Educação e Desporto. Secretaria da Educação Fundamental. Parâmetros curriculares nacionais primeiro e segundo ciclos do ensino fundamental. Brasília: MEC/SEF, 1997.

BRASIL. Ministério da Educação e Desporto. Secretaria da Educação Fundamental. Parâmetros curriculares nacionais terceiro e quarto ciclos do ensino fundamental: Educação Física. Brasília: MEC/SEF, 1998.

BRASIL. Ministério da educação e desporto. Secretaria da educação média e tecnológica. parâmetros curriculares nacionais: ensino médio. Brasília: Ministério da Educação, 1999.

BRASIL. Ministério da Educação, Secretaria de Educação Básica. Ensino fundamental de nove anos: orientações para a inclusão da criança de seis anos de idade. Brasília: MEC/SEB, 2007a.

BRASIL. Indagações sobre currículo: currículo, conhecimento e cultura. Brasília: MEC/SEB, 2007b.

CANDAU, Vera Maria. Formação continuada de professores: tendências atuais. In: MIZUKAMI, Maria das Graças; REALI, A. M. (Orgs.). Formação de professores: tendências atuais. São Carlos: Editora da UFSCar, 2003. p. 140-152.

CANDAU, Vera Maria. Sociedade multicultural: tensões e desafios. In: CANDAU, V. M. (Org.). Cultura(s) e educação: entre o crítico e o pós-crítico. Rio de Janeiro: DP\&A, 2005. p. 13-37.

CANEN, Ana. Educação multicultural, identidade nacional e pluralidade cultural: tensões e implicações curriculares. Cadernos de Pesquisa, São Paulo, n. 111, p. 135-149. 2000.

CANEN, Ana; OLIVEIRA, Ângela. Multiculturalismo e currículo em ação: um estudo de caso. Revista Brasileira de Educação, n. 21, p. 61-74. 2002.

CAPARROZ, Francisco. Eduardo. Parâmetros Curriculares Nacionais de Educação Física. In: BRACHT, Valter e CRISÓRIO, Ricardo (Orgs.). A educação física no Brasil e na Argentina: 
identidade, desafios e perspectivas. Campinas, SP: Autores Associados; Rio de Janeiro: Prosul, 2003.

CORAZZA, Sandra Maria. O que quer um currículo? pesquisas pós-críticas em educação. Petrópolis: Vozes, 2001.

CORAZZA, Sandra Maria. Pesquisa-ensino: o "hífen" da ligação necessária na formação docente. Araucárias: Revista do Mestrado em Educação da FACIPAL, Palmas, PR, v. 1, n. 1, p. 07-16, 2002.

DARIDO, Suraya Cristina. A Educação física, a formação do cidadão e os parâmetros curriculares nacionais. Revista Paulista de Educação Física. São Paulo, 15. p. 17- 32, 2001.

FORMOSINHO, João. O currículo uniforme pronto-a-vestir de tamanho único. Mangualde, Portugal: Edições Pedago, 2007.

FOUCAULT, Michel. As palavras e as coisas. São Paulo: Martins Fontes, 1981.

GARCIA, Regina Leite. Currículo emancipatório e multiculturalismo: reflexões de viagem. In: SILVA, Tomaz Tadeu da; MOREIRA, Antonio Flavio Barbora (Orgs.). Territórios contestados. Rio de Janeiro: Vozes. 2001. p. 114-143.

GARCÍA CANCLINI, Nestor. Culturas híbridas: estratégias para entrar e sair da modernidade. São Paulo: EDUSP, 2008.

GARCÍA CANCLINI, Nestor. Diferentes, desiguais e desconectados. Rio de Janeiro: Editora UFRJ, 2009.

GENTILI, Pablo. Neoliberalismo e educação: manual do usuário. In: SILVA, Tomaz Tadeu da.; GENTILI, Pablo. (Orgs.). Escola S.A: quem ganha e quem perde no mercado educacional do neoliberalismo. Brasília: CNTE, 1996. p. 9-49.

GIROUX, Henry. Atos impuros: a prática política dos estudos culturais. Porto Alegre: Artmed, 2006.

GIROUX, Henry. Praticando estudos culturais nas Faculdades de Educação. In: SILVA, Tomaz Tadeu da. (Org.). Alienígenas na sala de aula: uma introdução aos estudos culturais em educação. Rio de Janeiro: Vozes, 2008. p. 85-103.

GIROUX, Henry; SIMON, Roger. Cultura popular e pedagogia crítica: a vida cotidiana como base para o conhecimento. In: MOREIRA, Antônio Flávio Barbosa; SILVA, Tomaz Tadeu da. Currículo, cultura e sociedade. São Paulo: Cortez, 2005.

GRAMORELLI, Lilian Cristina; NEIRA, Marcos Garcia. Dez anos de Parâmetros Curriculares Nacionais: a prática da Educação Física na visão de seus atores. Movimento, Porto Alegre, v. 15, n. 04, p. 107-126, out.-dez. 2009

KINCHELOE, Joe; STEINBERG, Shirley. Repensar el multiculturalismo. Barcelona: Octaedro, 2012. 
LEITE, Carlinda. O lugar da escola e do currículo na construção de uma educação intercultural. In: CANEN, Ana; MOREIRA, Antônio Flávio Barbosa. Ênfases e omissões no currículo. Campinas: Papirus, 2001. p. 45-64.

MCLAREN, Peter. A vida nas escolas: uma introdução à pedagogia crítica nos fundamentos da Educação. Porto Alegre: Artmed, 1997.

McLAREN, Peter. Multiculturalismo crítico. São Paulo: Cortez, 2000.

McLAREN, Peter; GIROUX, Henry. Escrevendo das margens: geografias de identidade, pedagogia e poder. In: MCLAREN, Peter. Multiculturalismo revolucionário: pedagogia do dissenso para novo milênio. Porto Alegre: Artmed, 2000.

MIZUKAMI, Maria das Graças Nicoletti. Ensino: as abordagens do processo. São Paulo: EPU, 1986.

MOREIRA, Antônio Flávio Barbosa. A recente produção científica sobre currículo e multiculturalismo no Brasil (1995-2000): avanços, desafios e tensões. Revista Brasileira de Educação, Rio de Janeiro, n. 18, p. 65-81, set.-dez. 2001.

NEIRA, Marcos Garcia. Por um currículo multicultural da Educação Física. Presença Pedagógica, v. 12, p. 31-40. 2006.

NEIRA, Marcos Garcia. O ensino da Educação Física na Educação Básica: o currículo na perspectiva cultural. In: MOREIRA, Evando Carlos (Org.). Educação Física escolar: desafios e propostas. 2. ed. Jundiaí: Fontoura, 2009.

NEIRA, Marcos Garcia. A reflexão e a prática do ensino: educação física. São Paulo: Blucher, 2011.

NEIRA, Marcos Garcia. Práticas corporais: brincadeiras, danças, lutas, esportes e ginásticas. São Paulo: Melhoramentos, 2014.

NEIRA, Marcos Garcia; NUNES, Mário Luiz Ferrari. Educação física, currículo e cultura. São Paulo: Phorte, 2009.

NUNES, Mário Luiz Ferrari. Sobre Frankenstein, monstros e ben 10: fragmentos da formação em Educação Física. 2011, 277f. Tese (Doutorado em Educação) - Universidade de São Paulo. Faculdade de Educação. São Paulo, 2011.

PEREIRA, Ana. Educação multicultural: teorias e práticas. Porto: Asa, 2004.

SANT'ANNA, Denise. Benuzzi. É possível realizar uma história do corpo? In: SOARES, C. L. (Org.). Corpo e história. Campinas: Autores Associados. p 3-24. 2001.

SANTOS, Boaventura Sousa. Por uma concepção multicultural de direitos humanos. Lua Nova: Revista de Cultura e Política, n. 39, p. 105-124, 1997.

SANTOS, Boaventura Sousa. Renovar a teoria crítica e reinventar a emancipação social. São Paulo: Boitempo Editorial, 2007. 
SILVA, Tomaz Tadeu da. A Educação da Nova Direita e a Retórica da Qualidade Total. In: Identidades terminais. Petrópolis, RJ: Vozes, 1996.

SILVA, Tomaz Tadeu da. Documentos de identidade: uma introdução às teorias do currículo. Belo Horizonte: Autêntica, 2007.

SILVA, Tomaz Tadeu da. A produção social da identidade e da diferença. In: SILVA, Tomaz Tadeu da. (Org.) Identidade e diferença: a perspectiva dos Estudos Culturais. Petrópolis: Vozes, 2000.

STOER, Stephen. e CORTESÃO, Luiza. Levantando a pedra: da pedagogia inter/multicultural às políticas educativas numa época de transnacionalização. Porto: Afrontamento, 1999.

THERBORN, Göran. A crise e o futuro do capitalismo. In: GENTILI, Pablo. e SADER, Emir. (Orgs.). Pós-neoliberalismo: as políticas sociais e o Estado democrático. Rio de Janeiro: Paz e Terra, 1995.

TORRES SANTOMÉ, Jurjo. Globalização e interdisciplinaridade: o currículo integrado. Porto Alegre: Artmed, 1998.

WILLINSKY, John. Política educacional da identidade e do multiculturalismo. Cadernos de Pesquisa, São Paulo, n. 117, p. 29- 52, nov. 2002. 